Bangl. J. Vet. Med. (2011). 9 (2) : 167-175

\title{
MOLECULAR EPIDEMIOLOGICAL STUDIES ON ROTAVIRUS INFECTION CAUSING SEVERE DIARRHEA IN HUMAN, ANIMALS AND POULTRY
}

\author{
M. N. Alam ${ }^{1}$, M. M. Alam ${ }^{1}$, A. Nahar ${ }^{1}$ and N. Kobayashi ${ }^{2}$ \\ ${ }^{1}$ Department of Medicine, Faculty of Veterinary Science, Bangladesh Agricultural University, Mymensingh, \\ ${ }^{2}$ Department of Hygiene, School of Medicine, Sapporo Medical University, Sapporo, Japan
}

\begin{abstract}
The epidemiology of rotavirus infection in human, calves, sheep, goats and poultry were studied. Among total of 800 collected fecal samples , 320 samples from human, 125 samples from calves, 82 samples from sheep, 7 samples from goats, 267 samples from poultry were collected from July 2010 to May 2011 and examined by Polyacrylamide Gel Electrophoresis and Silver Staining (PAGE-SS) technique for the detection of presence of rotavirus dsRNA. Human rotavirus was detected $10.94 \%$ (35/320) in diarrhoeic fecal samples. The highest prevalence was recorded in September 33.33\% and the lowest in May 4.54\%. The prevalence of rotavirus infections was 33.33\% in autumn (September), $11.69 \%$ in late autumn (OctoberNovember), 9.6\% in winter (December-January), 9.72\% in spring (February- March), 6.12\% in summer (April-May) season in diarrhoeic samples indicated the presence of rotavirus in human round the year in Bangladesh and as such no marked seasonal variation in rotavirus infection in human. No calves, sheep and goat fecal sample was found positive for rotavirus on PAGESS technique. During the study period, 267 faecal samples (diarrhoeic and nondiarrhoeic) of chicken (from one day to one month of age) were tested and only one was found positive on PAGE-SS technique for rotavirus infection $(0.38 \%$; $1 / 267)$. The positive cases were found in samples collected in winter season from layer chicks aged 10 days. The migration patterns of detected positive strains were not similar on polyacrylamide gel electrophoresis and their migration speed was different types. Five electropherotypes were determined among 35 human rotavirus positive samples. All the electropherotypes were under group A and long pattern. The genome migration of avian rotavirus was distinct from human types and under group D and long pattern. In the present study, it was not investigated that bacteria, parasite or any other viruses which might be responsible for development of diarrhoea.
\end{abstract}

Key words: Rota virus, Epidemiology, Polyacrylamide Gel Electrophoresis and Silver Staining (PAGE-SS) and Electropherotype

\section{INTRODUCTION}

Rotavirus is distributed worldwide as an enteric pathogen in humans and animals (Yamamoto et al., 2011) including poultry (McNulty et al., 1983). Rotaviruses assume a special importance as etiologic agent of severe diarrhoeal illness in developing countries where malnutrition is common in young animals and children, and severe dehydration following rotavirus diarrhoea leads to a high rate of mortality (Black et al., 1982). Rotavirus infection in children, cow calves, buffalo calves (Alam et al., 1994), goat (Dey, 2003) have been reported in Bangladesh and recently rotavirus like virus detected in Bangladesh (Islam et al., 2009). Though the diseases occur in humans, animals and birds of all age group it is the most frequent and the most important malady in the young (Islam et al., 2009). Rotaviruses assume a special importance as etiologic agent of severe diarrhoeal illness in developing countries where malnutrition is common in young animals and children, and severe dehydration following rotavirus diarrhoea leads to a high rate of mortality (Black et al., 1982). In Bangladesh, calf diarrhea (gastroenteritis syndrome) remains the most often reported clinical problem in calf management and rearing system. The diarrhoeal disease is a great problem in goat also, causing a high rate of morbidity and mortality (Debnath et al., 1990). Rotavirus generally causes diarrhea in lambs and kids at 2 to 14 days of age (Susan, 2007). Besides in poultry rotavirus has already been established as the etiological agent of enteritis including diarrhoea and nutrient malabsorption (Snodgrass et al.,1986), which causes an decrease in feed conversion ratio and resulting large economic losses to poultry industry (Barnes, 1997). Avian rotavirus were first observed in feces of young turkey poults with diarrhoea and enteritis in South Dakota (Bergeland et al., 1977) and subsequently in diarrhoeic turkey poults in northern Ireland (McNulty et al., 1978) and in the diarrhoeic commercial hens in England (Jones et al., 1979). Poultry industry in our country is one of the few options that can successfully address employment generation, poverty alleviation and food security (Karim, 2007). But there are several constraints of poultry industries in Bangladesh including outbreaks of infectious

*Corresponding e-mail address:

Copyright (C) 2011 Bangladesh Society for Veterinary Medicine

All right reserved 1729-7893/0236/2011 


\section{N. Alam and others}

diseases causing economic loss and discouraging poultry rearing (Das et al., 2003). The term "molecular epidemiology" describes the application of biochemical methods to characterize viruses in an effort to understand the epidemiology of viral infections. The rotaviruses belonging to the family Reoviridae contain a genome of 11 segments of double stranded RNA (dsRNA) which can be separated into distinct bands by electrophoresis. The term "molecular epidemiology" describes the application of biochemical methods to characterize viruses in an effort to understand the epidemiology of viral infections. The rotaviruses belonging to the family Reoviridae contain a genome of 11 segments of double stranded RNA (dsRNA) which can be separated into distinct bands by electrophoresis. The migration pattern of the 11 genome segments following electrophoresis of the viral RNA in polyacrylamide gel is called the RNA electropherotype (Estes et al., 1984).

The RNA patterns of rotaviruses can be classified into two major distinctive groups; i.e., 'long' and 'short' RNA patterns in which the migration of segment 11 is rapid and slow, respectively (Kobayashi et al., 1989).Rotavirus strains can be distinguished on the basis of RNA electroapherotype because this marker is both characteristic and constant for a given virus strain (Steele and Alexandar, 1987 and Estes et al., 1984). Because of difficulty in the propagation of rotavirus in tissue culture, comparison of the migration patterns of RNA during polyacrylamide gel electrophoresis (PAGE) became an important laboratory technique for characterization of strains (Rodger et al., 1981). Polyacrylamide gel electrophoresis procedure provides a rapid, simple, reproducible method of obtaining rotaviral double stranded RNA preparations suitable for electrophoretic analysis in polyacrylamide gels. Detail studies on the epidemiology of rotavirus associated diarrhoea in human, animals and birds have been performed in advanced countries (Talukder, 1999). In Bangladesh limited works have been done in human and more limited in animals and poultry (Islam, 2007). In this country due to more close association of human, animal and poultry chances of zoonoses are extremely high and genetic mutation among the viruses of same genus and different strains of different hosts may cause a dangerous situation like avian influenza. So an extensive programmed epidemiological study of human, animals and poultry rotavirus infection still remain to be performed. Therefore, the present study was designed to investigate the prevalence of rotavirus infection in human, animals (e.g. calves, lambs and kids) and poultry (both in broiler and layer) and to analyze rotavirus RNA electropherotype in humans, animals and poultry and find their relationship.

\section{MATERIALS AND METHODS}

The present study was carried out during the period from January 2010 to May 2011 in the Laboratory of the Department of Medicine, Bangladesh Agricultural University (BAU), Mymensingh, Bangladesh.

\section{Collection of samples}

A total of 162 human samples were collected from September 2010 to May 2011 from SK hospital, Mymensingh and Mymensingh Medical College Hospital (MMCH), Mymensingh. Animal samples were collected from March 2010 to April 2011: 124 samples from calves from Bangladesh Agricultural University (BAU) Dairy Farm, surrounding areas of BAU, Chittagong Dairy Farm, Chittagong; Chittagong Veterinary and Animal Science University (CVASU) Dairy Farm; 82 samples from sheep , 7 samples from goat were collected from Bangladesh Livestock Research Institute (BLRI), Savar and a total of 267 poultry samples were collected from different poultry farms of Khagrachari Sadar, Shomboganj regions of Mymensingh Sadar Upazila and BAU surrounding areas. The freshly voided stool samples were collected in sterile screw capped containers and in possible cases the samples collected directly from the rectum of sheep, goat and cattle inserting fingers equipped with thin rubber hand gloves. The poultry samples were collected from litters which were freshly voided. The faecal materials were kept in a sterile, screw capped container. In all cases 5-10gms of sample were collected and precautions were taken to avoid contamination of one specimen with other. During sample collection, date of collection, age, sex, clinical signs, important clinical history and environmental situations were recorded. The samples were transported to the laboratory in container containing ice bag and stored at $-20^{\circ} \mathrm{C}$ (until used for electrophoresis) as quickly as possible.

\section{Preparation of $10 \%$ faecal suspension}

After thawing of the stored samples, $100 \mu \mathrm{l}$ of each specimen was taken in a labeled eppendorf tube and $900 \mu \mathrm{l}$ of phosphate buffer saline (PBS, pH-7.4) was added. Faeces and PBS was thoroughly suspended by using a vortex machine to prepare $10 \%$ solutions. The suspension was centrifuged at 15,000 rpm for 15 minutes and the supernatant was collected by micropipette and was either used freshly for next phase or stored at $-20^{\circ} \mathrm{C}$ for future use. 
Molecular epidemiological studies of rotavirus infection

\section{RNA extraction}

After thawing, the $10 \%$ solutions were thoroughly mixed, vortexed and centrifuged at 10,000 rpm for 10 minutes and the supernatant was collected. $300 \mu \mathrm{l}$ of supernatant fluid was collected separately in another eppendorf tube and $60 \mu \mathrm{l}$ of disrupting solution (6\% sodium dodecyl sulphate, 0.6\% 2-mercaptoethanol and $0.036 \mathrm{M}$ EDTA) was added by micropipette and vortexed for five seconds. Then the eppendorf tubes were incubated at $37^{\circ} \mathrm{C}$ for 30 minutes. After incubation, $500 \mu \mathrm{l}$ saturated phenol was added in each eppendorf tube and vortexed for five seconds. The eppendorf tube was then centrifuged at $10000 \mathrm{rpm}$ for 1 minutes. The supernatant was collected separately in another eppendorf tube. $16 \mu \mathrm{l}$ of $5 \mathrm{M}$ sodium chloride and $800 \mu \mathrm{l}$ of freezed ethanol were added in each eppendorf tube and vortexed. The RNA was precipitated at $-20^{\circ} \mathrm{C}$ for overnight or at $-80^{\circ} \mathrm{C}$ for two hours. (Steele and Alexander, 1987 and Dimitrov et al., 1984). After thawing, RNA was pelleted by centrifugation of the eppendorf tube at $10000 \mathrm{rpm}$ for 3 minutes. The liquid from the eppendorf was discarded. The RNA pellet was dried at $37^{\circ} \mathrm{C}$. The dried RNA suspended in $10 \mu \mathrm{l}$ of sample buffer $(0.12 \mathrm{M}$ Tris hydrochloride, $15 \%$ glycerol and $0.001 \%$ bromophenol blue).

\section{Polyacrylamide-Gel Electrophoresis and Silver Staining (PAGE-SS)}

Electrophoresis of the viral RNA was carried out in 10\% polyacrylamide gels. After preparing the gels in slabs, the two gel slabs were set on the electrophoresis chamber. Running buffer (pH-8.3; $0.25 \mathrm{M}$ Tris hydrochloride, $0.192 \mathrm{M}$ glycine, $0.001 \mathrm{M}$ EDTA) was poured on the chamber and in between the two slabs, $10 \mu \mathrm{l}$ of diluted RNA was loaded separately on the wells on the gels and the corresponding well was recorded. In one well in gel, RNA extracted from "Wa" strain of human rotavirus (HRV) grown in MA-104 cell culture (obtained from Sapporo Medical University, Japan) was loaded as control. The electrophoresis was performed at $20 \mathrm{mAmp}$ for 16 or 17 hours. After electrophoresis, the gels on separate trays were stained with staining solution $(0.011 \mathrm{M}$ silver nitrate) for 1 hour with continuous shaking. Then, the gels were washed three times in $200 \mathrm{ml}$ double distilled water for each washing. Finally the destaining step was performed by adding developing solution (7.5gm sodium hydroxide, $2 \mathrm{ml}$ formalin) in trays and with continuous shaking. The RNA bands appeared at this stage and destaining was continued until the bands were clearly visible. The discrete bands of 11 segmented double stranded RNA appeared in positive cases which are visible with naked eyes and viewer. The positive and negative all cases were documented properly and Keeping in view the objectives of the study, finally the results were arranged and analyzed where it seemed necessary.

\section{Electropherotyping}

The rotavirus electropherotypes were classified into two major distinctive groups, i.e. long patterns and short patterns, in which the migration of segment 11 rapid and slow, respectively (Kobayashi et al., 1989). Long and short electropherotypes were identified by comparing the migration pattern of RNA segment 11 with that of control "WA" strain (long electropherotype) and "SA11" strain (long electropherotype) of human rotavirus.before and after vaccination at 17 weeks, 21 weeks, 24 weeks and 28 weeks of age. Sera were separated and kept at $-20^{\circ} \mathrm{C}$ until use.

\section{RESULTS AND DISCUSSION}

In the present study the overall prevalence of rotavirus infection in human was $10.94 \%$ (35/320) shown in Table 1 which is in conformity with the earlier report of Paul et al. (2010) who detected rotavirus infection 11.9\% (171 of 1438) between July 2004 and June 2006 from Hospitalized children and adults with diarrhoea from SK Hospital, Mymensingh, Bangladesh. A total 124 samples collected from diarrhoeic calves were tested but no positive case of rota virus was found ( Table 1) whereas Dey (2003) reported 14.54\%, Selim (1985) showed 6.89\%, Samad and Ahmed (1990) also reported 12.10\% positive for rotavirus infection. A total of 82 sheep samples were tested and all found negative for rotavirus infection ( Table 1) wheres Susan (2007) stated that rotavirus generally causes diarrhea in lambs and kids at 2 to 14 days of age. A total of 7 goat samples were tested and all found negative (Table 1). However Dey (2003) reported 8.67\%, Talukder (1999) reported 6.18\% rotavirus infection in goat kids. The probable cause of these variations might be due to the presence of low amount of virus in specimens or absence of rotavirus particle in the faecal specimens or there is no prevalence of bovine rotavirus in the regions from where the samples were collected. Geographical distribution, climate, weather may also responsible for these variations. Avian rotavirus infection was found $0.38 \%(1 / 267)$ in poultry (Table 1). 


\section{N. Alam and others}

Table 1. Prevalence of rotavirus infection in human, animals and poultry of Bangladesh

\begin{tabular}{|cccc|}
\hline Name of the species & $\begin{array}{c}\text { No. of samples } \\
\text { tested }\end{array}$ & $\begin{array}{c}\text { No. of positive faecal } \\
\text { sample }\end{array}$ & $\begin{array}{c}\text { Prevalence of rotavirus in } \\
\text { individual species (\%) }\end{array}$ \\
\hline Human & 320 & 35 & 10.94 \\
Calves & 124 & 0 & 0 \\
Sheep & 82 & 0 & 0 \\
Goat & 7 & 0 & 0 \\
Poultry & 267 & 1 & 0.38 \\
\hline
\end{tabular}

In human, the prevalence of rotavirus infections in different months were $33.33 \%$ in September, $9.37 \%$ in October, $13.33 \%$ in November, 6.25\% December, 12.5\% in January, 15.15\% in February, 5.12\% in March, 7.4\% in April, $4.54 \%$ in May (Fig 1).

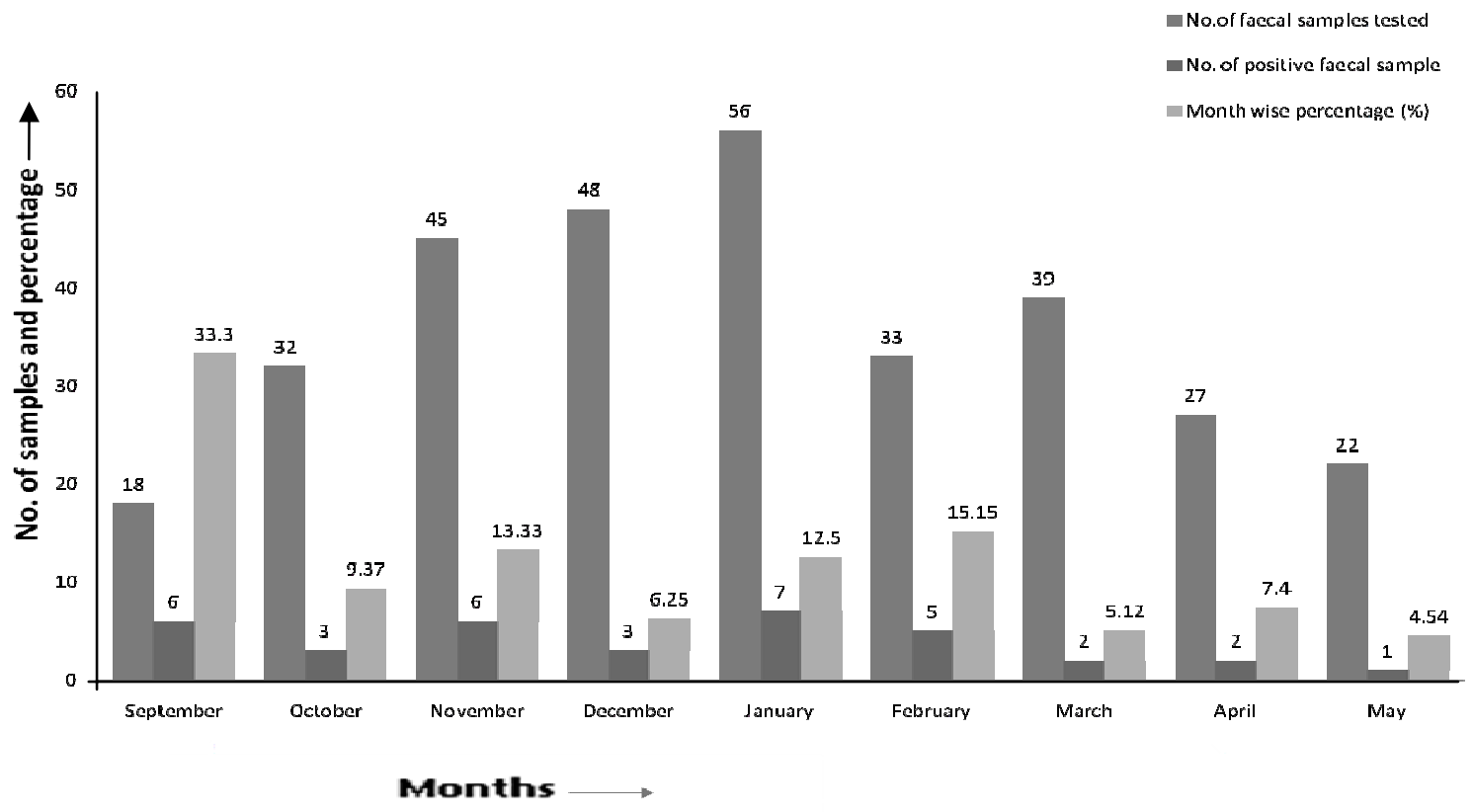

Fig. 1. Month wise prevalence of rotavirus infection in human

The highest prevalence 33.33\% was recorded in September while the lowest prevalence $4.54 \%$ was recorded in May. The prevalence of rotavirus infections was 33.33\% in autumn (September), $11.69 \%$ in late autumn (October-November), 9.6\% in winter (December-January), 9.72\% in spring (February- March) and $6.12 \%$ in summer (April-May) season in diarrhoeic samples (Fig 2). 


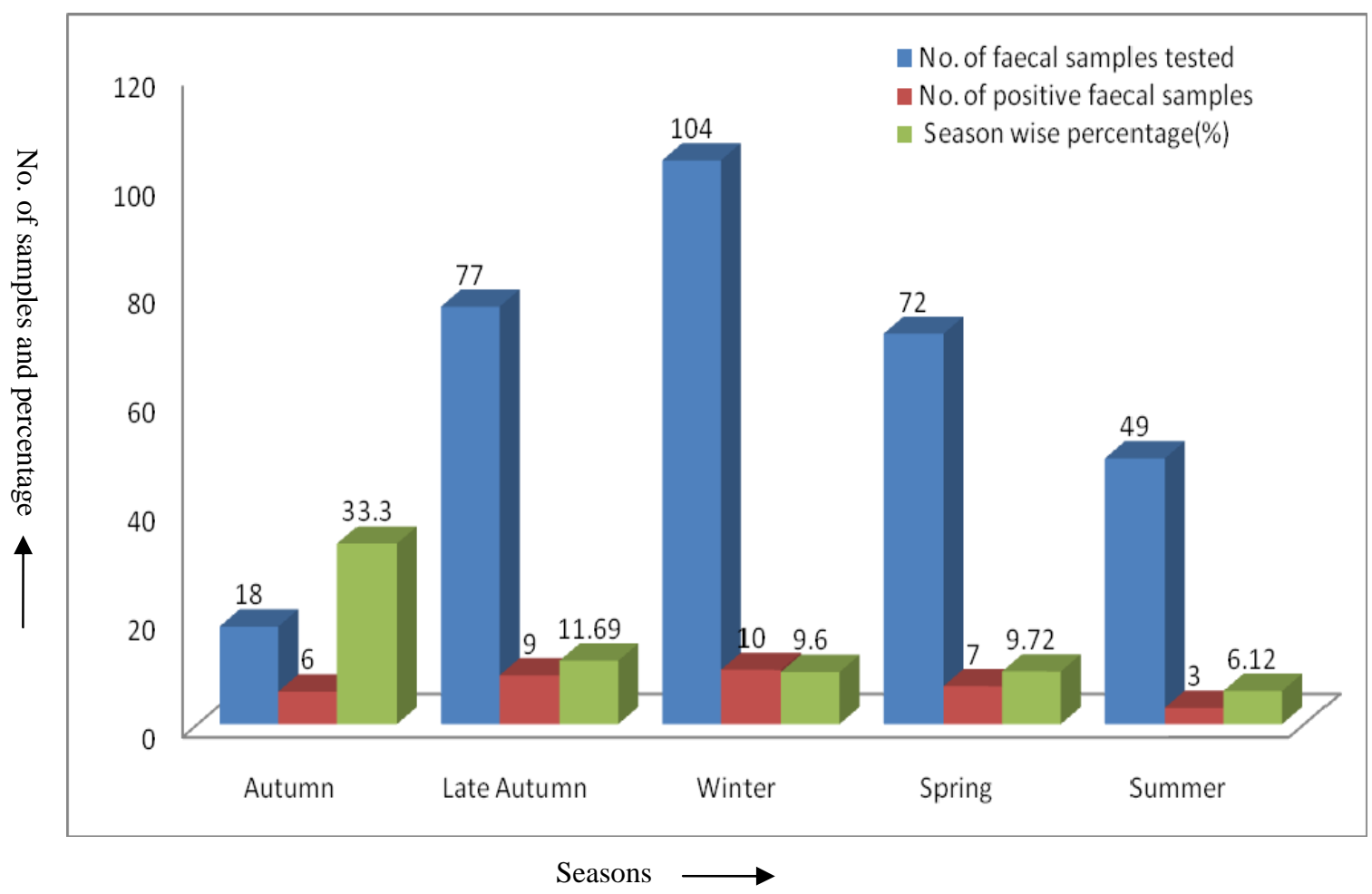

Fig. 2. Season wise prevalence of rotavirus infection in human

These results agree with the earlier reports of Alam et al. (1994) who reported prevalence rate of human rotavirus $16.0 \%$ to $18.18 \%$ during July to October. The higher rate in the months of January and February is an agreement with the findings of Islam et al., (2009) who conducted an epidemiological study on human patients and the prevalence of human rotavirus infection was high in winter, especially in the month of January. These results also agree with Wang et al. (2007), who carried out a study to observe seasonality for rotavirus diarrhea both in adults and children and showing overall rotavirus positive rates of 9.0 and $23.9 \%$, respectively in winter. The prevalence of human rotavirus infection in relation to sex has been shown in Table 2.

Table 2. Sex wise prevalence rotavirus infection in human

\begin{tabular}{|lccc|}
\hline Sex & No. of samples tested & No. of positive Faecal sample & Percent (\%) \\
\hline Male & 163 & 17 & 10.43 \\
Female & 157 & 18 & 11.46 \\
Total & 320 & 35 & 10.94 \\
\hline
\end{tabular}

Among the 320 human samples 163 (50.94\%) patients were male and 157 (49.06\%) were female. The detection of rotavirus was $10.43 \%$ (17/35) in male while female $11.46 \%$ (18/35). This indicated the prevalence of rotavirus infection was slightly higher in female than male. Among 267 chicks faecal samples (layer chicks 176 and broiler birds 91 and they were of one day old to one month of age), one fecal sample $(0.38 \%$; $1 / 267)$ was found positive for rotavirus on PAGE-SS technique. This positive sample was collected from 10 days old chick in winter season. This observation is inconformity with the earlier report of Samad and Ahmed (1990) who reported high rate of rotavirus infection in the winter season and Alam et al. (1994) reported highest rate $26.32 \%$ in winter season. The lower rate of rotavirus infection has been documented by Ahmed (2004) who found only $0.86 \%$ rotavirus like virus infection in diarrhoeic broiler chicks in Bangladesh (Mymensingh and Gazipur) and 


\section{N. Alam and others}

Karim (2007) found $13.81 \%$ samples had rotavirus infection. The probable reasons of this result might be due to the presence of very low amount of virus in samples or absence of rotavirus particle in the faecal samples. Moreover, there might have infection with other diarrhea causing enteropathogens. Among the 35 positive human samples, five different electropherotypes were detected. This result correlates with the report of Paul et al. (2010) who found 11 different electropherotype by polyacrylamide gel electrophoresis (PAGE) but is inconformity with the earlier report of Ahmed (2004) who found only one electropherotype. Electrophoretic migration pattern of human and avian rotavirus dsRNA in polyacrylamide gel has been shown in Fig. 3. The RNA electrophoretic migration pattern of human rotavirus and avian rotavirus were typical of rotavirus RNA electrophoretic migration pattern characteristics to human rotavirus and avian rotavirus respectively. The genome migration of avian rotavirus was distinct from human electropherotypes. Polyacrylamide gel electrophoresis to demonstrate the viral RNA segment is a sensitive and specific, fast and low cost technique, which can be easily implemented in low-outfitted laboratories for the screening of rotavirus infection in poultry (Villareal et al., 2006). The rotavirus RNA segments have been divided into four size classes: class I (segments 1-4), class II (segments 5 and 6), class III (segments 7, 8 and 9) and class IV (segments 10 and 11). The long pattern and short pattern depends on the migration of $10^{\text {th }}$ and $11^{\text {th }}$ segments. Depending on the migration pattern of dsRNA the electropherotypes have been classified as A1, A2, A3, A4, and A5 in positive samples (Fig. 4). Among the 35 positive human samples electropherotype A1 was detected in 6 samples, A2 in 5 samples, A3 in 13 samples, A4 in 4 samples, A5 in 7 samples and the only poultry positive sample was electropherotype B1. In cases of genome migration pattern of human rotavirus type A1: in class I segment 1 and segment 4 were migrated separately and segment 2 and 3 were migrated as close spaced couplet ; in class II, $5^{\text {th }}$ and $6^{\text {th }}$ segments were migrated separately but distance was short; in class III, the segments 7, 8 and 9 migrated as close spaced couplet and in class IV, the segments 10 and 11 were migrated separately but distance is long pattern . In type A2, genome migration pattern of human rotavirus is similar to type A1 exception where segments 7 and 8 were migrated as close spaced couplet and segment 9 was migrated separately. In case of genome migration pattern of human rotavirus type A3: in class I, segment 1 was migrated separately but lower level compare to type 1 and type 2; migration pattern of segments 2 and 3 was similar to that of type A1 and segment 4 was similar to type A2 and the segments 5 and 6 were migrated separately and the gaps were more than types 1 and 2; class III similar to type 2; class IV similar to previous types but the $11^{\text {th }}$ segment was migrated more distance. In case of genome migration pattern of human rotavirus type $\mathbf{A 4}$, class I similar to type 2; the class II similar to type 1 and 2 ; class III similar to type 2 and 3 and class IV similar to type 1 and 2. In genome migration pattern of human rotavirus type A5, class I similar to type 2 and 4; the class II similar to type 1, 2 and 4; the class III similar to type 1 and class IV class similar to types 1,2 and 4 . In case of genome migration pattern of avian rotavirus type B1, in class I segment 1 and 2 were migrated separately and segment 3 and 4 were migrated in close spaced couplet ; in class II, $5^{\text {th }}$ and $6^{\text {th }}$ segments migrated separately but distance short; in class III, the segments 7,8 and 9 migrated as close spaced couplet and in class IV, segments 10 and 11 were migrated separately. Total 5 human electropherotypes and 1 avian electropherotype were long pattern. Electropherotypic analysis of rotavirus in polyacrylamide gel electrophoresis has been used as a molecular approach to distinguish strains and to obtain information on their epidemiological significance (Kalica et al., 1976; Rodger and Holmes, 1979 and Schnagl et al., 1976).

As rotaviruses, rotaviruses like viruses and atypical viruses have segmented double-stranded RNA (dsRNA) genomes that can be distinguished by distinct pattern after electrophoresis (Theil et al., 1985). In the present study, it was not investigated whether bacteria, parasites or any other viruses causing diarrhea were associated. Thus it remained unclear whether the rotavirus alone produced diarrhoea in human, animal and poultry or any other causal agents were responsible for diarrhea. From the present study it may be concluded that the prevalence of rotavirus infection was much higher in human than poultry. All the rotaviruses detected from human were group A and from birds were group D. 
Molecular epidemiological studies of rotavirus infection

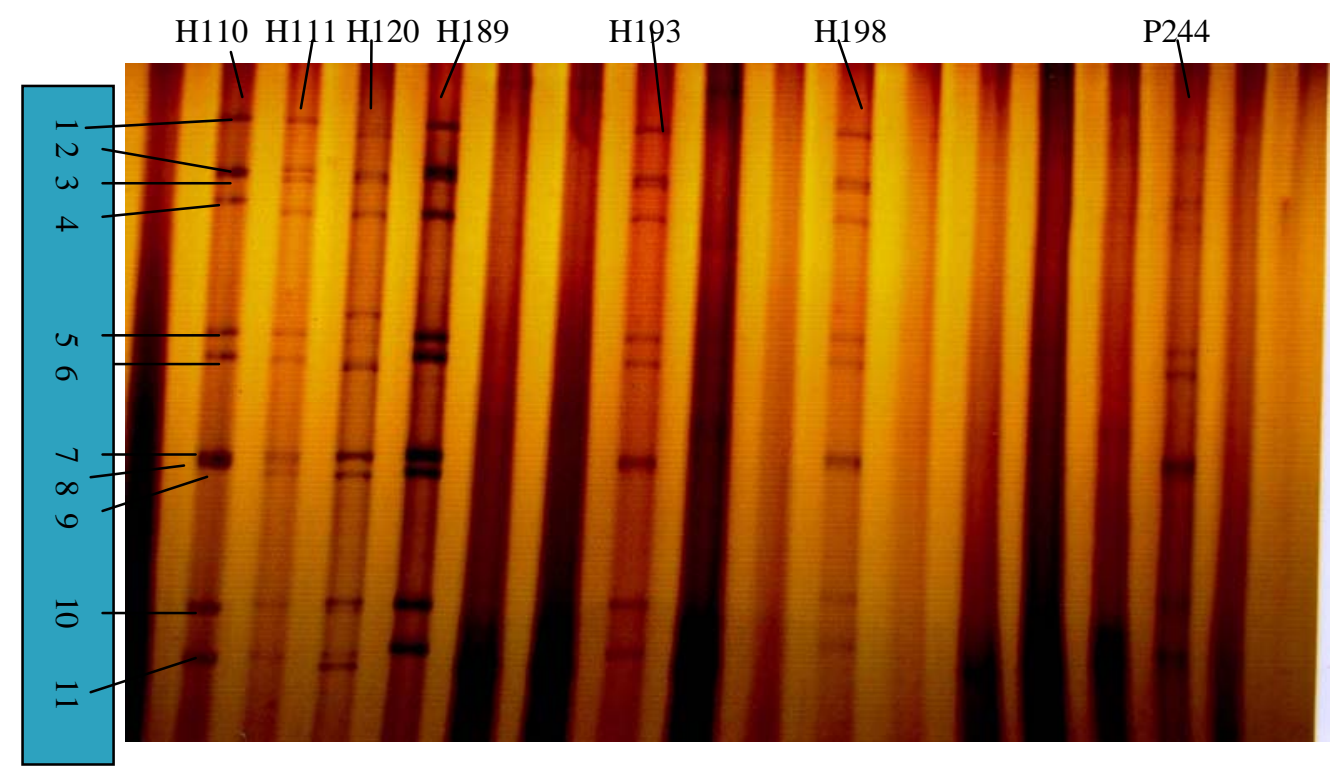

Fig 3. Electrophoretic migration pattern of human and avian rotavirus dsRNA in polyacrylamide gel. In the left side 1-11 numbers are indicated the dsRNA segments. In the upper portion of the figure H110, H111, H120, H189, H193, H198 are indicated the human sample numbers and P224 indicating poultry sample number.

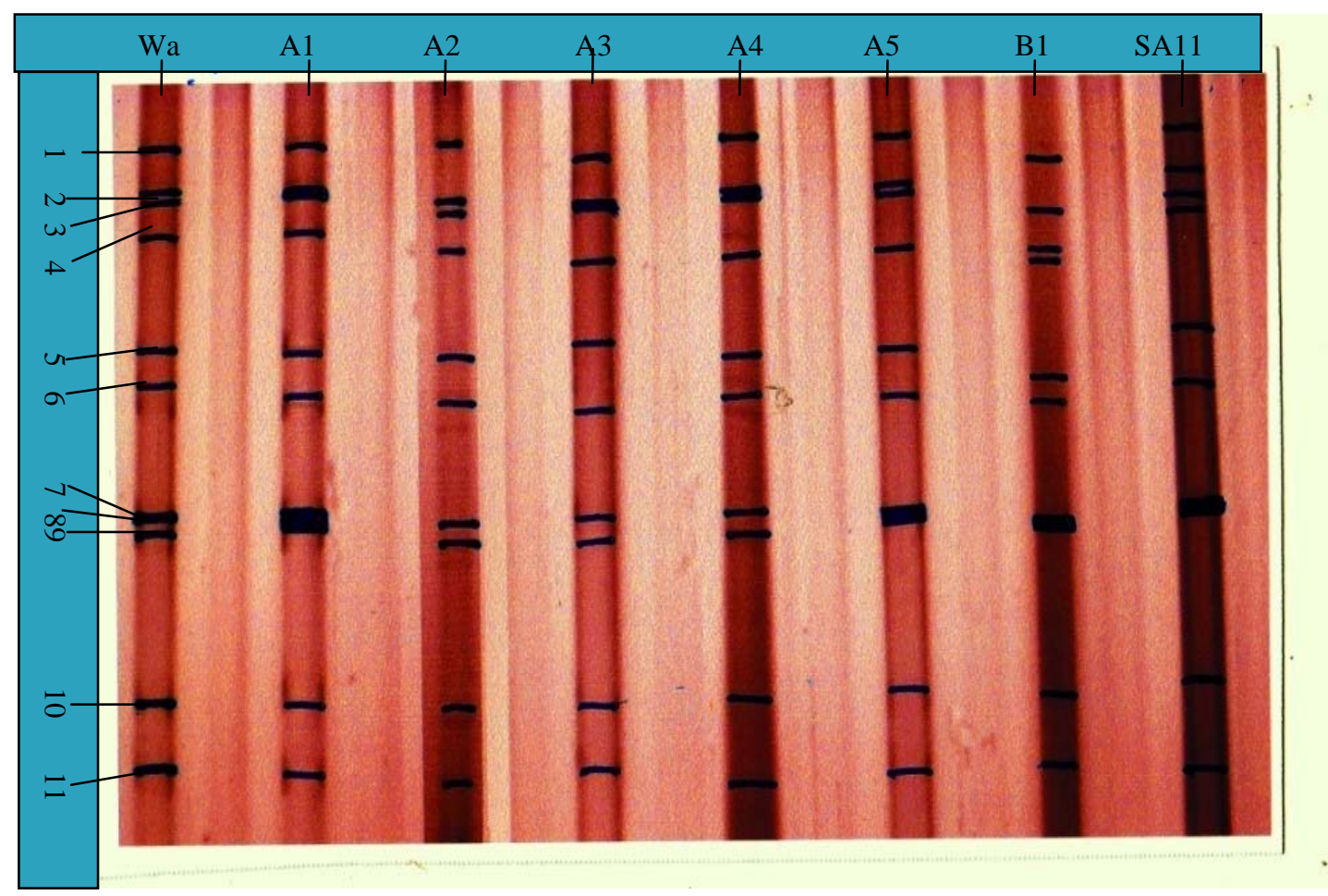

Fig 4. Electropherotype of human and avian rotavirus dsRNA in polyacrylamide gel. In the left side 1-11 numbers are indicated the dsRNA segments. In the upper portion of the figure A1, A2, A3, A4, A5, B1 indicating the different electropherotype. 


\section{N. Alam and others}

Difference of rotavirus distribution in male and female was not remarkable. The highest prevalence was recorded in September 33.33\% and the lowest in May 4.54\%.The prevalence of rotavirus infections was 33.33\% in autumn (September), 11.69\% in late autumn (October-November), 9.6\% in winter (December-January), 9.72\% in spring (February- March), 6.12\% in summer (April-May) season in diarrhoeic samples. Only the long pattern of dsRNA of rotaviruses was found in this study. Five electropherotypes were detected in human rotavirus and one different electropherotype detected in poultry. The understanding of complete epidemiological features with regards to transmission between human, animal and avian rotavirus is most essential before introduction of human rotavirus vaccine in Bangladesh. In these regard further studies of human, animal and avian rotaviruses should be continued in different parts of the country to know the real status of rotavirus infection in Bangladesh, to understand the genetic diversity and evolutionary mechanisms of human rotavirus to develop a strategy for prevention of rotavirus associated diarrhoea.

\section{REFERENCES}

1. Ahmed MS (2004). Detection of avian rotavirus like virus in broiler chickens in Mymensingh and Gazipur. MS Thesis, Department of Medicine Bangladesh Agricultural University, Mymensingh, Bangladesh.

2. Alam MM, Huque AKM, Nigar S, Haque M, Choudhury NS and Ahmed MU (1994). Rotavirus infection in children and Calves in associated with acute gastroenteritis. Bangladeh Veterinary Journal 28: 35-40.

3. Barnes HJ (1997). Virology of enteric infections. Diseases of poultry. 10th edn., Iowa state University press, Ames, pp. 685-686.

4. Bergeland ME, McAdaragh JP and Stotz I (1977). Rotaviral enteritis in turkey poults. Proceedings of Western Poultry Diseases. pp. 129-130.

5. Black RE, Brown KH, Becker S, Alim ARMA and Huq I (1982). Longitudinal studies of infectious diseases and physical growth of children in rural Bangladesh. II. Incidence of diarrhoea and association with known pathogens. American Journal of Epidemiology 115: 315-324.

6. Das PM, Rajib DMM, Noor M and Islam MR (2003). Retrospective analysis on the proportional incidence of poultry diseases in greater Mymensingh district of Bangladesh. In proceeding of 4th International Poultry Show and Seminar, from February 28 to March 2, 2003, held in Bangladesh China Friendship Conference Centre, Agargaon, Dhaka, Bangladesh. pp: 35-39.

7. Debnath NC, Sit BK, Selun SA, Prodhan MAM and Howlader MR (1990). A retrospective study of calf mortality and morbidity in small holder traditional farms in Bangladesh. Preventive Veterinary Medicine 9: 1-7.

8. Dey BK (2003). Molecular epidemiologic studies on rotaviruses in calves, goats and poultry birds. M.S. Thesis, Department of Medicine, Bangladesh Agricultural University, Mymensingh, Bangladesh.

9. Dimitrov DH, Graham DY, Lopez J, Muchinik G, Velasco G, Stenback WA and Estes MK (1984). RNA electropherotypes of human rotaviruses from North and South America. Bulletine of WHO 62(2): 321-329.

10. Estes MK, Graham DY and Dimitrov DH (1984). The molecular epidemiology of rotavirus gastroenteritis. Progressive Medical Virology 29: 1-22.

11. Islam MS (2007). Molecular Epidemiologic study on rotavirus infection in human and birds in associated with gastroenteritis. MS Thesis, Department of Medicine, Bangladesh Agricultural University, Mymensingh, Bangladesh.

12. Islam MS, Alam MM, Ahmed MU, Saifuzzaman ABM, Kobayashi N, Kayesh MEH and Uddin MS (2009). Molecular epidemiological study on rotavirus infection in human and birds in association with gastroenteritis. Bangladesh Journal of Veterinary Medicine 7(1):233-237.

13. Jones RC, Hughes CS and Henry RR (1979). Rotavirus infection in commercial laying hens. Veternary Record 104: 22.

14. Kalica AR, Garon CF, Wyatt RG, Mebus CA, Van Kirk DH, Chanock RM and Kapikian AZ (1976). Differentiation of human and calf reovirus like agents associated with diarrhoea using polyacrylamide gel electrophoresis of RNA. Virology 74: 84-92.

15. Karim MR (2007). Survey on the distribution of avian rotavirus by polyacrylamide gel electrophoorsis. MS Thesis, Department of Medicine, Bangladesh Agricultural University, Mymensingh, Bangladesh.

16. Kobayashi N, Lintag LC, Tangiguchi K, Saniel MC and Urasawa S (1989). Unusual human rotavirus strains having subgroup 1 specificity and long RNA electrophoerotype. Archives of virology 109:11-23. 
17. McNulty MS, Allan GM and Stuart JC (1978). Rotavirus infection in avian species. Veterinary Record 103: 319-320.

18. McNulty MS, Allan GM and McCracken RM (1983). Experimental infection of chickens with rotaviruses: Clinical and Virological findings. Avian Pathology 12: 45-54.

19. Paul SK, Hossain MA, Mahmud MC, Ahmed S, Hossain MA, Nandi AK and Tabassum S (2010). Instability of human rotavirus $\mathrm{G}$ genotypes circulating in a rural area of Bangladesh. Mymensingh Medical Journal 20(1):1-8.

20. Rodger SM and Holmes IH (1979). Comparison of the genome of simian, bovine and human rotaviruses by gel electrophoresis and detection of genomic variation among bovine isolates. Journal of Virology 30: 839-846.

21. Rodger SM, Bishop RF, Birch C, McLean B and Holmes IH (1981). Molecular epidemiology of human rotaviruses in Melbourne, Australia, from 1973 to 1979, as determined by electrophoresis of genome ribonucleic acid. Journal of Clinical Microbiology 13(2): 272-278.

22. Samad MA and Ahmed MU (1990).Epidemiological investigation of rotavirus infection in buffalo calves in Bangladesh. Journal of clinical microbiology 11:530-532.

23. Schnagl RD and Holmes IH (1976). Characterization of the genome of human infantile enteritis virus (rotavirus). Journal of Virology 19: 267-270.

24. Selim SA (1985). Prevalence of rotavillis infection in the selected areas of Bangladesh. MS Thesis, Department of Microbiology and Hygiene, Bangladesh Agricultural University, Mymensingh, Bangladesh.

25. Snodgrass DR, Terzolo HR, Sherwood D, Campbell I, Menzies JD and Synge BA (1986). Etiology of diarrhoea in young calves. Veterinary Record 119:31-34.

26. Steele AD and Alexandar JJ (1987). Molecular epidemiology of rotavirus in black infants in South Africa. Journal of Clinical Microbiology 25 (12): 2384-2387.

27. Susan Schoenian (2007). Small Ruminant Info. Sheet. University of meryland extension. 17:8-1.

28. Talukder RI (1999). Rotavirus diarrrhoea in human and animals in Mymensingh. MS Thesis, Department of Medicine, Bangladesh Agricultural University, Mymensingh, Bangladesh.

29. Theil KW, Reynolds DL and Saif YM (1985). Isolation and serial propagation of Turkey rotaviruses in a Fetal Rhesus Monkeys Kidney (MA 104) cell line. Avian Diseases 30: 93-104.

30. Villarreal LYB, Uliana G, Valenzuela C, Chacon JLV, Saidenberg ABS, Sandches AA, Brandao PE, Jerez JA and Ferreira AJP (2006). Rotavirus detection and isolation from chickens with or without symptoms. Brazilian Journal of Poultry Science 8:3.

31. Wang YH, Kobayashi N, Zhou DJ, Yang ZQ, Zhou X, Peng JS, Zhu ZR, Zhao DF, Liu MQ and Gong J (2007). Molecular epidemiologic analysis of group A rotaviruses in adults and children with diarrhea in Wuhan city, China, 2000-2006. Archives of Virology 152 (4): 669-685.

32. Yamamoto D, Ghosh S, Kuzuya M, Wang YH, Zhou X, Chawla-Sarkar M, Paul SK, Ishino M and Kobayashi N (2011). Whole-genome characterization of human group C rotaviruses: identification of two lineages in the VP3 gene. The journal of general virology 92(2):361-9. 